\title{
Lenalidomide and dexamethasone in treatment of patients with relapsed and refractory multiple myeloma - analysis of data from the Czech Myeloma Group Registry of Monoclonal Gammopathies
}

\author{
V. MAISNAR ${ }^{1, *}$, Z. STEFANIKOVA ${ }^{2}$, I. SPICKA ${ }^{3}$, L. POUR ${ }^{4}$, J. MINARIK ${ }^{5}$, M. FLOCHOVA ${ }^{6}$, J. RADOCHA ${ }^{1}$, E. GREGORA ${ }^{7}$, N. STECOVA ${ }^{8}$, T. JELINEK ${ }^{9}$, \\ A. JUNGOVA ${ }^{10}$, E. KRALIKOVA ${ }^{11}$, L. BROZOVA ${ }^{12}$, R. HAJEK ${ }^{9}$
}

${ }^{1} 4$ th Department of Medicine - Hematology, Faculty Hospital and Charles University in Hradec Kralove, Czech Republic; ${ }^{2}$ Department of Clinical Hematology, University Hospital and Comenius University in Bratislava, Slovakia; ${ }^{3} 1$ st Department of Medicine - Clinical Department of Hematology of the First Faculty of Medicine and General Teaching Hospital Charles University, Czech Republic; ${ }^{4}$ Department of Internal Medicine, Hematology and Oncology, University Hospital Brno and Faculty of Medicine Masaryk University, Czech Republic; ${ }^{5}$ Department of Hemato-Oncology, University Hospital Olomouc and Faculty of Medicine and Dentistry, Palacky University Olomouc, Czech Republic; ${ }^{6}$ Department of Hematology and Transfusiology, University Hospital and Comenius University in Martin, Slovakia; ${ }^{7}$ Department of Internal Medicine and Hematology, 3rd Faculty of Medicine, Charles University and Faculty Hospital Kralovske Vinohrady, Prague, Czech Republic; ${ }^{8}$ Department of Hematology and Transfusiology, Luis Pasteur University Hospital in Kosice, Slovakia; ${ }^{9}$ Department of Hematooncology, University Hospital Ostrava and Faculty of Medicine University of Ostrava, Czech Republic; ${ }^{10}$ Hematology and Oncology Department, Charles University Hospital Pilsen, Czech Republic; ${ }^{11}$ Department of Hematology and Transfusiology, F. D. Roosevelt Faculty Hospital in Banska Bystrica, Slovakia; ${ }^{12}$ Institute of Biostatistics and Analyses, Faculty of Medicine, Masaryk University, Brno, Czech Republic

${ }^{*}$ Correspondence: maisnar@seznam.cz

Received August 24, 2018 / Accepted December 5, 2018

\begin{abstract}
Lenalidomide (LEN) is an immunomodulator with clinical activity against myeloma cells. Based on the pivotal phase 3 trials MM-009 and MM-010, the combination of lenalidomide and dexamethasone(DEX) was approved for patients with multiple myeloma who received at least one prior therapy. Here, we evaluated LEN/DEX therapy in whole population and subsequently in selected sub-groups of patients with relapsed/refractory multiple myeloma followed in the Monoclonal Gammopathy Registry of the Czech Myeloma Group. 858 patients were treated with LEN/DEX in Czech Republic and Slovakia until end of 2017. The analyzed sub-groups were defined as patients with high-risk cytogenetic aberrations and patients with relapsed and refractory MM. The ORR (response better than PR) in whole group of patients was $46.3 \%$ for all lines of therapy, $26.4 \%$ for high-risk group and $32.1 \%$ for relapsed and refractory group. Overall survivals (OS) in the same sets were as follows: 25.6, 15.7 and 18.5 months respectively, progression free survival (PFS) was 11.2, 6.4 and 9.0 months, respectively. The most common adverse events were hematologic and infectious. In conclusion, we found our results correlated with those in other studies in terms of OS, PFS and also of treatment toxicity.
\end{abstract}

Key words: lenalidomide, dexamethasone, multiple myeloma, relapse, refractory, cytogenetic aberrations

Multiple myeloma (MM) is a malignant plasma cell disorder characterized by the uncontrolled proliferation of monoclonal plasma cells in the bone marrow $[1,2]$. It constitutes approximately $1 \%$ of all reported neoplasms and approximately $13 \%$ of hematologic cancers worldwide [1]. In the US, Canada and Western European countries, approximately 5 to 7 new cases of MM are diagnosed per 100.000 people every year $[1,3,4]$. The risk of MM developing increases with age, the median age at diagnosis is 69 years [1].

Although the survival of MM patients has dramatically improved over the last 2 decades because of newer and more effective treatment options - such as bortezomib, thalidomide, and lenalidomide - the disease remains incurable. Despite the impressive gains observed in MM, the improvements have not been uniform and prognosis continues to vary considerably on the basis of a variety of prognostic factors [5]. Patients who relapse after their initial therapy demonstrate variable response to subsequent treatments, with decreasing likelihood and duration of response. Various studies have also demonstrated that the cytogenetic characteristics detected by FISH are among the most powerful prognostic markers in myeloma patients. MM with the highrisk cytogenetic abnormalities, $\operatorname{del}(17 \mathrm{p}), \mathrm{t}(14 ; 16)$ and/or 
$t(4 ; 14)$, are characterized by short survival related to an early relapse rate and rapid development of mechanisms of resistance to multiple agents [6-11].

LEN is approved in combination with dexamethasone by the European Medicines Agency (EMA) in adults whose disease has been treated at least once in the past. It is an immunomodulatory drug for the treatment of $\mathrm{MM}$ as a more potent derivative of thalidomide with a different toxicity profile [12]. It exhibits immunomodulatory, antiangiogenic, and direct apoptotic properties [13]. The second line LEN/DEX combination was shown to significantly improve the overall response rate (ORR) and to extend progression free survival (PFS), time to progression (TTP) and overall survival (OS) in relapsed/ refractory multiple myeloma $(\mathrm{r} / \mathrm{r}$ MM) compared to placebo plus DEX [14]. Long term follow-up as well as subset analysis of two phase 3 randomized placebo-controlled studies (MM-009 and MM-010) have shown also that LEN/DEX significantly prolongs overall survival [15-18].

The aim of the analysis is to evaluate the efficacy and safety of LEN/DEX in real world setting.

\section{Patients and methods}

Registry of Monoclonal Gammopathies (RMG) was founded by Czech Myeloma group (CMG) in 2007. The registry is intended for collecting clinical data concerning the diagnosis and treatment results of patients with monoclonal gammopathies in Czech Republic and Slovakia. The CMG Registry of Monoclonal Gammopathies currently contains data of 5.905 patients with multiple myeloma. Signed informed consent is obtained from every patient prior to inclusion into registry. The data were entered in an electronic registry form by authorized medical staff. Adverse events were collected according common terminology criteria.

This was retrospective, non-interventional analysis. In the analysis were included patients diagnosed with $\mathrm{r} / \mathrm{r} \mathrm{MM}$, who received 1-3 prior therapies and were treated outside of clinical trials. Totally we analyzed data from $858 \mathrm{MM}$ patients treated with LEN/DEX in Czech Republic and Slovakia until end of 2017. Most patients were treated by standard dosage during each 28-day cycle patients received LEN $25 \mathrm{mg}$ once a day on days 1-21 and DEX $40 \mathrm{mg}$ once a week, in patients over 75 years of age we often used reduced dosage - LEN $15 \mathrm{mg}$ and DEX $20 \mathrm{mg}$ [1].

The disease stage was assessed according to Durie-Salmon and the international staging system ISS was applied to score the prognosis. The cytogenetic testing was performed in certified laboratories using FISH. The baseline characteristics and the outcomes were evaluated for all selected lines of therapy and also for sub-groups: high-risk with the presence at least one aberration from $t(4 ; 14), t(14 ; 16)$ or $\operatorname{del}(17 p)$, relapsed and refractory MM with patients refractory to at least one prior line and at the same time was not refractory to at least one line.
Standard descriptive statistics were applied in the analysis, absolute and relative frequencies for categorical variables and median supplemented by $5^{\text {th }}$ and $95^{\text {th }}$ percentile for continuous variables. The endpoints of analysis were ORR, PFS and OS. The ORR was defined as collective proportion of patients with stringent complete remission (sCR), complete remission (CR), very good partial remission (VGPR) and partial remission (PR) defined by IMWG [5]. The PFS and OS were estimated by Kaplan-Meier analysis (median and $95 \%$ confidence interval - CI) [19]. The analysis was carried out in the SPSS software (IBM Corp. 2016, Version 24.0, Armonk, NY).

\section{Results}

The median age of the whole group of patients at start of the treatment was 67 years (range 19-90 years), for high risk group 65 years ( $40-80$ years) and for relapsed and refractory group 67 years (range 19-85 years). $49.6 \%$ of patients had 1 prior line of therapy, $34.5 \%$ of patients had 2 prior lines and $15.7 \%$ of patients had 3 prior lines before LEN/DEX. Median of previous lines of therapy was 2 . In the first line, the majority of patients were treated with bortezomib regimen; $40 \%$ of patients underwent autologous transplantation within the previous treatment. In most patients (833 treatment lines from total 892; 93.4\%) therapy with thalidomide or bortezomib preceded LEN/DEX regimen in any previous line (but not strictly in the first line of therapy).

Median LEN/DEX treatment duration was 6.6 months (max. 80.8). The dose of LEN at start of treatment in one application was $25 \mathrm{mg}$ in $77.3 \%$ of patients. 135 (15\%) patients were older than 75 years, the median dose of lenalidomide and dexamethasone in these patients was $15 \mathrm{mg}$ and $20 \mathrm{mg}$, respectively. The median follow-up from the start of LEN/DEX regimen to the date of the last evaluation was 14.6 months (max. 103.9). Detailed demographic and baseline characteristics of the evaluated patients are summarized in Table 1.

The final response to treatment is evaluated only for terminated treatments. A total of $758(85 \%)$ treatments were completed to time of analysis. The treatment was most often terminated due to the valid limitations that were applied to lenalidomide therapy by state regulators and insurance companies in Czech Republic and Slovakia (maximum 8-10 cycles; only 2 more cycles after CR achievement; the possibility to continue treatment only if at least PR was achieved after 4 cycles of LEN/DEX therapy). Treatment with lenalidomide until disease progression was only approved from 2016. The second most frequent reason for the termination of treatment was the progression of disease $(22.8 \%)$; in $16.5 \%$ of patients was the reason for treatment termination the occurrence of an $\mathrm{AE}$ (treatment toxicity).

The ORR (response to therapy better than PR) in whole group of patients was $46.3 \%$ for all lines of therapy (sCR 0.3, CR 3.7, VGPR 18.1 and PR 24.2\%), 26.4\% for high-risk group (sCR 1.9, CR 3.8, VGPR 13.2 and PR 7.5\%) and 32.1\% 
Table 1. Baseline characteristics of patients at the start of treatment - total and within the defined subsets.

\begin{tabular}{|c|c|c|c|}
\hline Baseline characteristics at the start of treatment ${ }^{1}$ & Whole group of patients & High-risk group $^{3}$ & Rel. and ref. group ${ }^{4}$ \\
\hline Age (start of treatment) & $\mathrm{n}=\mathbf{8 9 2}$ & $\mathrm{n}=72$ & $\mathrm{n}=184$ \\
\hline$\leq 65(\%)$ & $365(41.5)$ & $40(55.6)$ & $82(45.1)$ \\
\hline$>65(\%)$ & $515(58.5)$ & $32(44.4)$ & $100(54.9)$ \\
\hline$>75(\%)$ & $135(15.1)$ & $25(34.7)$ & $33(17.9)$ \\
\hline Average (SE) & $66.1(0.3)$ & $62.4(1.2)$ & $65.6(0.8)$ \\
\hline Median (min-max) & $67(19-90)$ & $65(40-80)$ & $67(19-85)$ \\
\hline Sex & $\mathrm{n}=\mathbf{8 9 2}$ & $\mathrm{n}=72$ & $\mathrm{n}=184$ \\
\hline Women (\%) & $426(47.8)$ & $40(55.6)$ & $96(52.2)$ \\
\hline Men $(\%)$ & $466(52.2)$ & $32(44.4)$ & $88(47.8)$ \\
\hline Time from diagnosis (months) & $\mathrm{n}=\mathbf{8 7 6}$ & $\mathrm{n}=72$ & $\mathrm{n}=181$ \\
\hline Average (SE) & $38.8(1.1)$ & $28.3(2.5)$ & $45.2(2.4)$ \\
\hline Median & 29.1 & 23.4 & 34.9 \\
\hline Follow-up time from the start of treatment (months) & $\mathrm{n}=\mathbf{8 8 0}$ & $\mathrm{n}=72$ & $\mathrm{n}=182$ \\
\hline Average (SE) & $19.9(0.6)$ & $17.8(2.0)$ & $19.2(1.4)$ \\
\hline Median & 14.6 & 10.7 & 12.8 \\
\hline ECOG PS & $\mathrm{n}=790^{\star}$ & $n=67$ & $n=161$ \\
\hline $0(\%)$ & $82(10.4)$ & $6(9.0)$ & $13(8.1)$ \\
\hline $1(\%)$ & $524(66.3)$ & $40(59.7)$ & $107(66.5)$ \\
\hline$\geq 2(\%)$ & $184(23,2)$ & $21(31,4)$ & $41(21.1)$ \\
\hline ISS & $n=689^{*}$ & $n=62^{\star}$ & $\mathrm{n}=146^{*}$ \\
\hline I (\%) & $298(43.3)$ & $30(48.4)$ & $47(32.2)$ \\
\hline II (\%) & $207(30.0)$ & $20(32.3)$ & $53(36.3)$ \\
\hline III (\%) & $184(26.7)$ & $12(19.4)$ & $46(31.5)$ \\
\hline Serum creatinine $(\mu \mathrm{mol} / \mathrm{L})$ & $\mathrm{n}=\mathbf{8 9 2}$ & $\mathrm{n}=72$ & $\mathrm{n}=184$ \\
\hline$>176(\%)$ & $101(12.3)$ & $5(7.2)$ & $28(16.1)$ \\
\hline$t(4 ; 14)^{2}$ & $\mathrm{n}=244^{\star}$ & $\mathrm{n}=57^{\star}$ & $\mathrm{n}=50^{*}$ \\
\hline Positive (\%) & $35(14.3)$ & $35(61.4)$ & $5(10.0)$ \\
\hline$t(14 ; 16)^{2}$ & $\mathrm{n}=200^{*}$ & $\mathrm{n}=32^{\star}$ & $\mathrm{n}=41^{*}$ \\
\hline Positive (\%) & $14(7.0)$ & $14(43.8)$ & $1(2.4)$ \\
\hline $\operatorname{del}(17 p)^{2}$ & $\mathrm{n}=251^{\star}$ & $\mathrm{n}=62^{\star}$ & $\mathrm{n}=48^{*}$ \\
\hline Positive (\%) & $37(14.7)$ & $37(59.7)$ & $8(16.7)$ \\
\hline Chromosomal aberration ${ }^{2,3}$ & $\mathrm{n}=197^{\star}$ & $\mathrm{n}=72$ & $\mathbf{n}=37^{\star}$ \\
\hline Standard risk (\%) & $125(63.5)$ & $0(0.0)$ & $24(64.9)$ \\
\hline High risk (\%) & $72(36.5)$ & $72(100.0)$ & $13(35.1)$ \\
\hline Number of prior lines & $\mathrm{n}=892$ & $\mathrm{n}=72$ & $\mathrm{n}=184$ \\
\hline $1(\%)$ & $444(49.8)$ & $35(48.6)$ & $0(0.0)$ \\
\hline $2(\%)$ & $308(34.5)$ & $24(33.3)$ & $109(59.2)$ \\
\hline $3(\%)$ & $140(15.7)$ & $13(18.1)$ & $75(40.8)$ \\
\hline Average (SE) & $1.7(0.0)$ & $1.7(0.1)$ & $2.4(0.0)$ \\
\hline Status of $\mathbf{M M}^{4}$ & $\mathrm{n}=\mathbf{8 9 2}$ & $\mathrm{n}=72$ & $\mathrm{n}=184$ \\
\hline Relapsed (\%) & $604(67.7)$ & $45(62.5)$ & $0(0.0)$ \\
\hline Refractory (\%) & $104(11.7)$ & $14(19.4)$ & $0(0.0)$ \\
\hline Relapsed and refractory (\%) & $184(20.6)$ & $13(18.1)$ & $184(100.0)$ \\
\hline
\end{tabular}

${ }^{1}$ The categorical variables described using $\mathrm{n}(\%)$ and the continuous variables described using the average ( $\mathrm{SE}=$ standard error) and median

${ }^{2}$ Samples for the evaluation of the positivity of chromosomal aberrations taken at the time of the diagnosis of multiple myeloma

${ }^{3}$ Standard risk=absence of $\mathrm{t}(4 ; 14)$ and $\mathrm{t}(14 ; 16)$ and del(17p13); high-risk=the positivity of at least one evaluated abnormality

${ }^{4}$ Refractory $\mathrm{MM}=$ progression during treatment or within 60 days from its termination

- Relapsed=the patient was refractory to none of the prior lines

- Refractory=the patient was refractory to all the prior therapies

- Relapsed and refractory=the patient was refractory to at least one prior line and at the same time was not refractory to at least one line

* The parameters with more than $10 \%$ of values missing:

ISS, International Staging System; ECOG PS, Performance Status developed by the Eastern Cooperative Oncology Group; and present multiple myeloma chromosomal aberrations 
for relapsed and refractory group (CR 2.9, VGPR 12.4 and PR $16.8 \%$ ). Minimal response (MR) was reached at $6.6 \%$ in whole group of patients, $1.9 \%$ in high-risk group and 9.5\% in relapsed and refractory group. Within the evaluated groups, the median OS was 25.6 months [95\% CI=23.028.3] for whole population; 15.7 months [ $95 \% \mathrm{CI}=8.2-23.3$ ] for patients with high-risk cytogenetics; 18.5 months [95\%
$\mathrm{CI}=14.2-22.8]$ for relapsed and refractory MM patients. The results of Kaplan-Meier analysis for OS are presented on Figure 1. Median PFS was 11.2 months [95\% CI=10.312.1] for whole population, 6.4 months [ $95 \% \mathrm{CI}=4.8-7.9]$ for the high-risk group and 9.0 months [95\% CI=6.3-11.6] for patients with relapsed and refractory MM. The results of Kaplan-Meier analysis for PFS are presented on Figure 2.

A

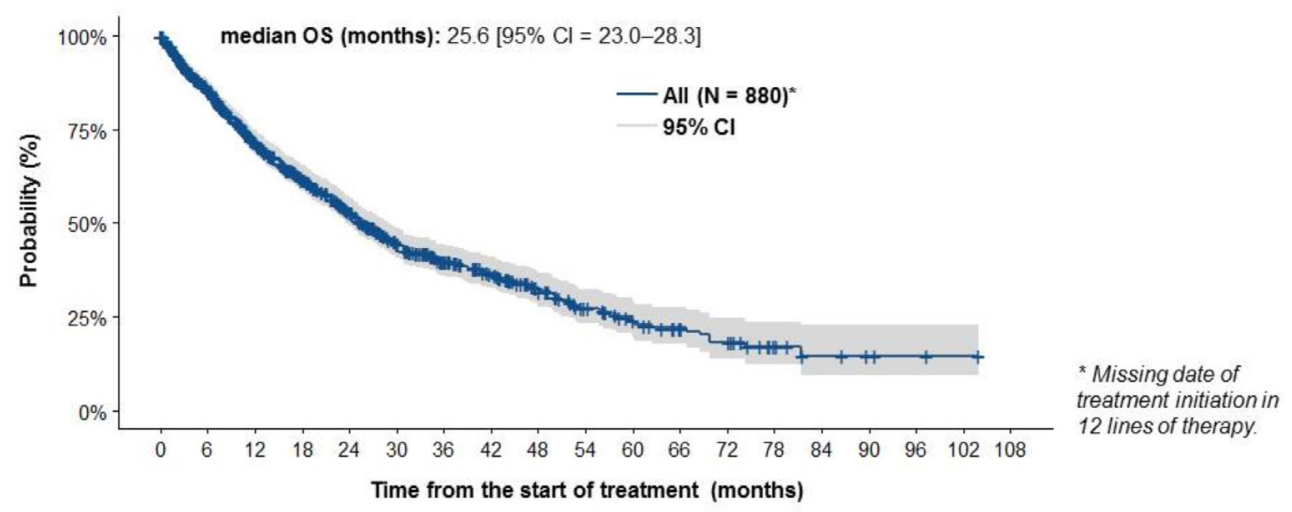

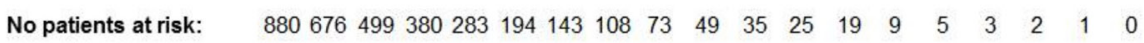

B

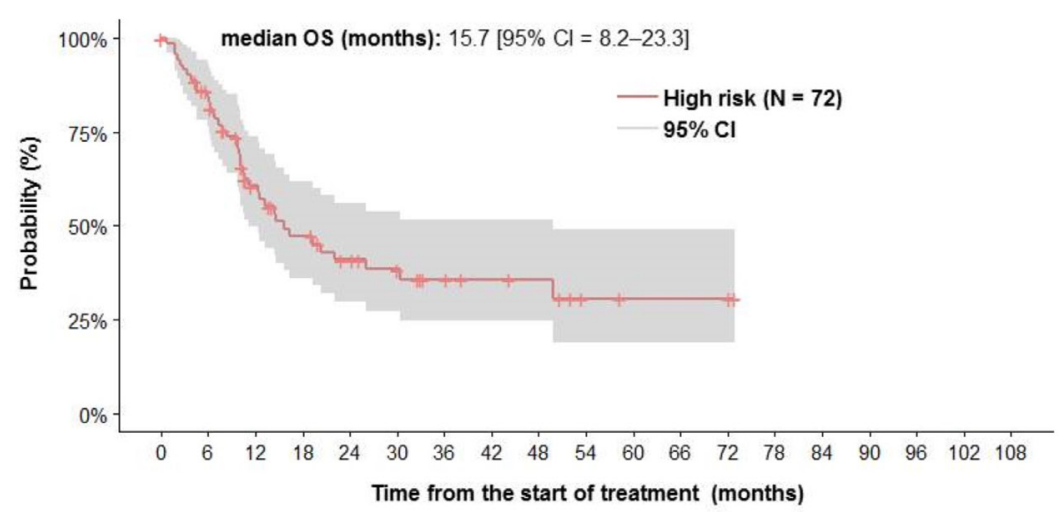

$\begin{array}{lllllllllllllllllllll}\text { No patients at risk: } & 72 & 58 & 33 & 24 & 18 & 15 & 10 & 8 & 7 & 3 & 2 & 2 & 2 & 0 & 0 & 0 & 0 & 0 & 0\end{array}$

C

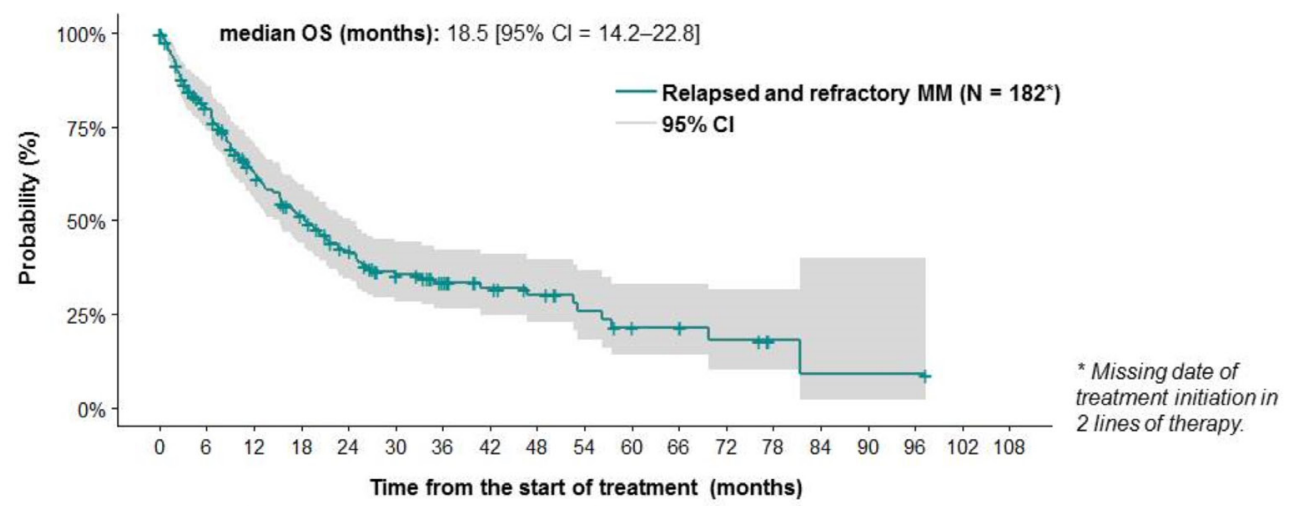

$\begin{array}{llllllllllllllllllllll}\text { No patients at risk: } & 182 & 132 & 96 & 73 & 55 & 39 & 29 & 21 & 17 & 12 & 9 & 8 & 5 & 2 & 1 & 1 & 1 & 0 & 0\end{array}$

Figure 1. Overall survival (OS). A) whole group, B) high-risk group (presence of $t(4 ; 14)$ or $t(4 ; 16)$ or del(17p13) at the time of diagnosis), C) relapsed and refractory group. 
The most frequent grade $3-5$ adverse events (AEs) in whole group of patients were neutropenia $(n=171 ; 19.2 \%)$, infectious complications $(\mathrm{n}=126 ; 14.1 \%)$, anemia $(\mathrm{n}=117 ; 13.1 \%)$, and thrombocytopenia $(\mathrm{n}=107 ; 12.0 \%)$. For the high-risk group: thrombocytopenia $(n=16 ; 22.2 \%)$, neutropenia $(n=14$; $19.4 \%)$, infectious complications $(\mathrm{n}=10 ; 13.9 \%)$ and anemia $(\mathrm{n}=8 ; 11.1 \%)$ were the most frequent grade $3-5$ AEs. In the relapsed and refractory MM subgroup the most frequent grade 3-5 AEs were: neutropenia $(n=53 ; 28.8 \%)$, anemia $(\mathrm{n}=35 ; 19.0 \%)$, infectious complications $(\mathrm{n}=30 ; 16.3 \%)$, and thrombocytopenia $(\mathrm{n}=29 ; 15.8 \%)$. Grade 5 toxicity (associated with the death of the patient) was recorded in 5 patients $(0.6 \%)$ during lenalidomide treatment, it was 1 infectious cause and 4 other causes. We observed significantly higher

A

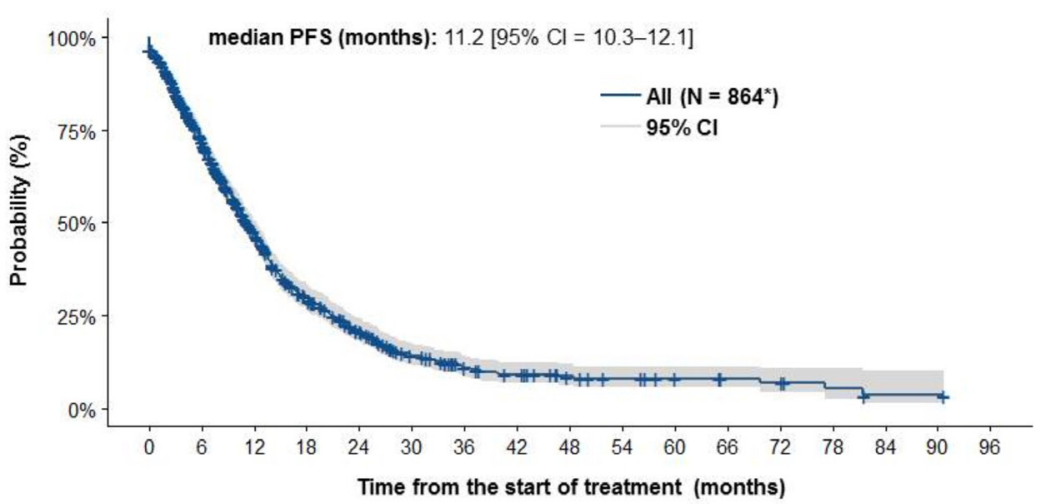

${ }^{*}$ Missing date of treatment initiation / disease progression in 28 lines of therapy.

$\begin{array}{lllllllllllllllllll}\text { No patients at risk: } & 864 & 553 & 314 & 181 & 109 & 60 & 35 & 26 & 17 & 13 & 10 & 7 & 6 & 3 & 1 & 1 & 0\end{array}$

B

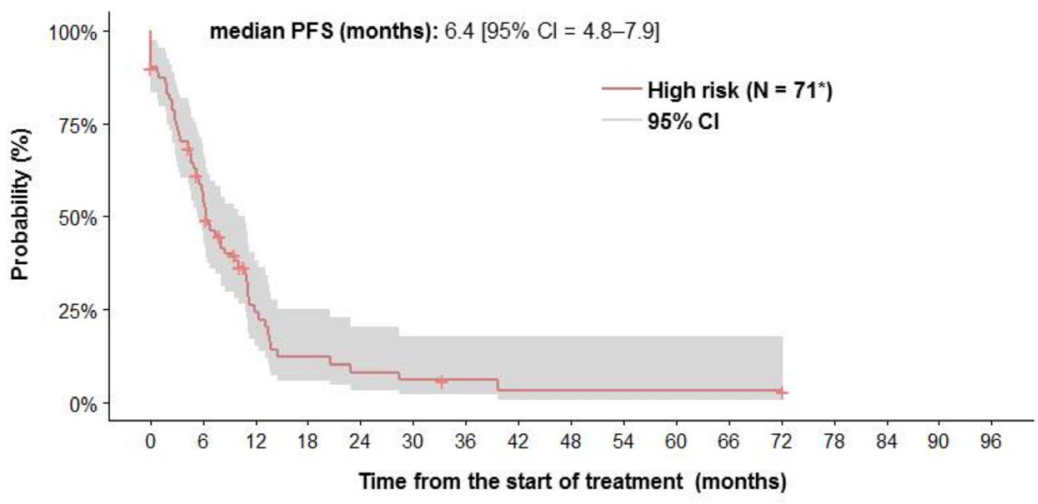

* Missing date of treatment initiation / disease progression Time from the start of treatment (months)

$\begin{array}{lllllllllllllllllll}\text { No patients at risk: } & & 71 & 38 & 12 & 6 & 4 & 3 & 2 & 1 & 1 & 1 & 1 & 1 & 1 & 0 & 0 & 0 & 0\end{array}$

C

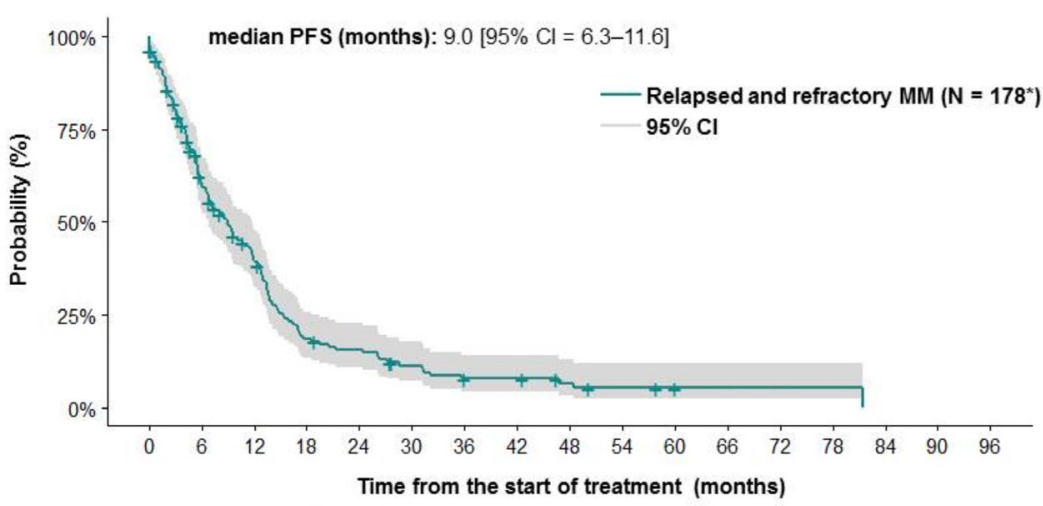
initiation / disease progression in 6 lines of therapy.

No patients at risk:

$\begin{array}{lllllllllllllllll}178 & 96 & 59 & 27 & 22 & 13 & 8 & 8 & 5 & 3 & 2 & 1 & 1 & 1 & 0 & 0 & 0\end{array}$

Figure 2. Progression free survival (PFS). A) whole group, B) high-risk group, C) relapsed and refractory group. 
grade of thrombocytopenia and neutropenia in case of $25 \mathrm{mg}$ lenalidomide dose $(p<0.001)$. The most common cause of death during follow-up after treatment was disease progression $(70.5 \%)$, the cause of death for the remaining approximately $1 / 4$ of the patients were most often infections.

\section{Discussion}

Multiple myeloma remains an incurable form of hematologic malignancy, but early diagnosis, well-adjusted therapies, and intense treatment can prolong overall patient survival. Previous studies have shown the important role of LEN/DEX as the therapy in patients with relapsed multiple myeloma [16][18][20]. The combination of LEN/DEX today forms the basis of very effective triplet regimen (for example CRd with carfilzomib resp. DRd with daratumumab) which in most cases are more effective than bortezomib based regimen [21].

The LEN/DEX combination is currently the most used regimen for treatment of refractory/relapsed MM in Czech Republic and Slovakia. The primary objective of our analysis was to compare the results achieved in real world setting with results of clinical trials. Our overall results are still little worse, due to the limitations that were applied to lenalidomide therapy by state regulators and insurance companies in Czech Republic and Slovakia. It is only from 2016 that we can administer lenalidomide in relapsed and refractory MM patients until the next disease progression. The PFS and OS medians of two sub-groups (high-risk cytogenetics and relapsed and refractory $\mathrm{MM}$ ) are also comparable with results previously published in the MM-009 and MM-010 phase 3 studies as well as safety study MM-016 [22]. Kneppers et al. reported OS 22 months in heavily pre-treated patients with a median of 3 previous lines of therapy which is comparable with our results of 25.6 months [14]. Our results confirmed that the high-risk set with cytogenetic abnormalities was a predictor of poor treatment outcome and decreased overall survival of 15.7 months. These patients should preferably be treated by triplet regimen in combination with proteasome inhibitor [21].

The LEN/DEX regimen is an established treatment particularly suitable for frail and elderly patients because of its minimal toxicity. Lenalidomide, a derivative of thalidomide, is less toxic and more potent than the parent drug. The report of 10 years Czech Myeloma Group experience with thalidomide therapy in MM patients was published by our group before [23]. Nearly one third of patients in our trial had previously received thalidomide. Our data indicate similarly as MM-009 and MM-010 trial data that lenalidomide can be administered to patients who have received thalidomide therapy before without deterioration of preexisting thalidomide-related neuropathy. The primary toxic effects of the lenalidomide regimen are hematologic, and we found them well manageable.

In summary, we confirm in real world setting that LEN/ DEX is effective regimen with minimal toxicity in patients with relapsed or refractory multiple myeloma. The main benefit and at the same time the limitation of this analysis is the reflection of real clinical practice in the use of lenalidomide in the Czech Republic and Slovakia in previous years. When, due to valid limitations, it was not possible to achieve results as with lenalidomide treatment until disease progression.

Acknowledgements: Supported by program PROGRES Q40/08. We would like also to thank all the patients who agreed on the inclusion of their data in the CMG Registry of monoclonal gammopathies. Special thanks to the data managers and research nurses who have significantly contributed to data acquisition and completion.

\section{References}

[1] PALUMBO A, ANDERSON K. Multiple myeloma. N Engl J Med 2011; 364: 1046-1060. https://doi.org/10.1056/NEJMra1011442

[2] ROLLING C, KNOP S, BORNHAUSER M. Multiple myeloma. Lancet 2015; 385: 2197-2208. https://doi.org/10.1016/ S0140-6736(14)60493-1

[3] LANDGREN O, WEISS BM. Patterns of monoclonal gammopathy of undetermined significance and multiple myeloma in various ethnic/racial groups: support for genetic factors in pathogenesis. Leukemia 2009; 23: 1691-1697. https:// doi.org/10.1038/leu.2009.134

[4] HAROUSSEAU JL, DREYLING M, ESMO GUIDELINES WORKING GROUP. Multiple myeloma: ESMO clinical recommendations for diagnosis, treatment and follow-up. Ann Oncol 2008; 19 (Suppl 2): 55-57. https://doi.org/10.1093/annonc/mdn088

[5] RAJKUMAR SV, HAROUSSEAU JL, DURIE B, ANDERSON KC, DIMOPULOS $M$ et al. Consensus recommendations for the uniform reporting of clinical trials: report of the International Myeloma Workshop Consensus Panel 1. Blood 2011; 117: 4691-4695. https://doi.org/10.1182/ blood-2010-10-299487

[6] AVET-LOISSEAU H, ATTAL M, MOREAU P, CHARBONNEL C, GARBAN F et al. Genetic abnormalities and survival in multiple myeloma: the experience of the Intergroupe Francophone du Myelome. Blood 2007; 109: 3489-3495. https://doi.org/10.1182/blood-2006-08-040410

[7] BERGSAGEL PL, MATEOS MV, GUTIERREZ NC, RAJKUMAR SV, SAN MIGUEL JF. Improving overall survival and overcoming adverse prognosis in the treatment of cytogenetically high-risk multiple myeloma. Blood 2013; 121: 884-892. https://doi.org/10.1182/blood-2012-05-432203

[8] GERTZ MA, LACY MQ, DISPENZIERI A, GREIPP PR, LITZOW MR et al. Clinical implications of $\mathrm{t}(11 ; 14)$ (q13;q32), $\mathrm{t}(4 ; 14)(\mathrm{p} 16.3 ; \mathrm{q} 32)$, and $-17 \mathrm{p} 13$ in myeloma patients treated with high-dose therapy. Blood 2005; 106: 2837-2840. https:// doi.org/10.1182/blood-2005-04-1411

[9] MIKHAEL JR, DINGLI D, ROY V, REEDER CB, BUADI FK et al. Management of newly diagnosed symptomatic multiple myeloma: updated Mayo Stratification of Myeloma and RiskAdapted Therapy (mSMART) consensus guidelines 2013. Mayo Clin Proc 2013; 88: 360-376. https://doi.org/10.1016/j. mayocp.2013.01.019 
[10] AVET-LOISSEAU H, ATTAL M, CAMPION L, CAILlOT D, HULIN C et al. Long-term analysis of the IFM 99 trials for myeloma: cytogenetic abnormalities $[\mathrm{t}(4 ; 14)$, del $(17 \mathrm{p})$, 1q gains] play a major role in defining long-term survival. J Clin Oncol 2012; 30: 1949-1952. https://doi.org/10.1200/ JCO.2011.36.5726

[11] DIMOPOULOS M, KASTRITIS E, CHRISTOULAS D, MIGKOU M, GAVAVRIATOPOULOU $\mathrm{M}$ et al. Treatment of patients with relapsed/refractory multiple myeloma with lenalidomide and dexamethasone with or without bortezomib: prospective evaluation of the impact of cytogenetic abnormalities and of previous therapies. Leukemia 2010; 24 : 1769-1778. https://doi.org/10.1038/leu.2010.175

[12] BARLETT J, DREDGE K., DALGLEISH AG. The evolution of thalidomide and its IMiD derivatives as anticancer agents. Nature Reviews Cancer 2004; 4(4): 314-322. https://doi. org/10.1038/nrc1323

[13] TAGEJA N. Lenalidomide - current understanding of mechanistic properties. Anticancer Agents Med Chem 2011; 11: 315-326.

[14] KNEPPERS E, LOKHORST H, EELTINK C, HULS G, KERSTEN M J et al. Analysis of efficacy and prognostic factors of lenalidomide treatment as part of a Dutch compassionate use program. Clin Lymphoma Myeloma Leuk 2010; 10: 138-143. https://doi.org/10.3816/CLML.2010.n.020

[15] DIMOPOULOS M, CHEN C, SPENCER A, NIESVIZKY $\mathrm{R}$, ATTAL $\mathrm{M}$ et al. Long-term follow-up on overall survival from the MM-009 and MM-010 phase III trials of lenalidomide plus dexamethasone in patients with relapsed or refractory multiple myeloma. Leukemia 2009; 23: 2147-2152. https://doi.org/10.1038/leu.2009.147

[16] DIMOPOULOS M, SPENCER A, ATTAL M, PRINCE HM, HAROUSSEAU JL et al. Lenalidomide plus dexamethasone for relapsed or refractory multiple myeloma. $\mathrm{N}$ Engl J Med 2007; 357(21): 2123-32. https://doi.org/10.1056/NEJMoa070594
[17] STADTMAUER EA, WEBER DM, NIESVIZKY R, BELCH, $A R$, PRINCE $M$ et al. Lenalidomide in combination with dexamethasone at first relapse in comparison with its use as later salvage therapy in relapsed or refractory multiple myeloma. Eur J Haematol 2009; 82: 426-432. https://doi. org/10.1111/j.1600-0609.2009.01257.x

[18] WEBER DM, CHEN C, NIESVIZKY R, WANG M, BELCH $\mathrm{AR}$ et al. Lenalidomide plus dexamethasone for relapsed multiple myeloma in North America. N Engl J Med 2007; 357: 2133-2142. https://doi.org/10.1056/NEJMoa070596

[19] KAPLAN EI, MEIER P. Nonparametric estimation from incomplete observations. J Am Stat Assoc 1958; 53: 457-481.

[20] PALUMBO A, DIMOPOULOS M, SAN MIGUEL JF, HAROUSSEAU JL, ATTAL $M$ et al. Lenalidomide in combination with dexamethasone for the treatment of relapsed or refractory multiple myeloma. Blood Reviews 2009; 23: 87-93. https://doi.org/10.1016/j.blre.2008.07.003

[21] MAGAROTTO V, BRINGHEN S, OFFIDANI M, BENEVOLO G, PATRIARCA $F$ et al. Triplet versus doublet lenalidomide-containing regimens for the treatment of newly diagnosed multiple myeloma. Blood 2016; 127: 1102-1108. https://doi.org/10.1182/blood-2015-08-662627

[22] CHEN C, REECE DE, SIEGEL DS, NIESVIZKY R, BOCCIA $\mathrm{RV}$ et al. Expanded safety experience with lenalidomide plus dexamethasone in relapsed or refractory multiple myeloma. Br J Haematol 2009; 146(2): 164-70.

[23] MINARIK J, SANDECKA V, MAISNAR V, GREGORA E, SPICKA I et al. 10 years of experience with thalidomide in multiple myeloma patients: Report of the Czech Myeloma Group. Leuk Res 2013; 37(9): 1063-9. 